REVISTA DE GEOCIÊNCIAS DO NORDESTE

Northeast Geosciences Journal

v. $6, n^{\circ} 2(2020)$

ISSN: $2447-3359$

https://doi.org/10.21680/2447-3359.2020v6n2ID19303

\title{
EROSÕES LINEARES NO SEMIÁRIDO PERNAMBUCANO: AVALIAÇÃO DE UMA PARCELA EROSIVA EM MICROESCALA NA DEPRESSÃO SÃO FRANCISCANA
}

\author{
Joaquim Pedro de Santana Xavier ${ }^{1}$; Edilson \\ Amaral Tavares Coutinho²; Kaio César de \\ Oliveira Tavares ${ }^{3}$; Danielle Gomes da Silva \\ Listo $^{4}$; Fabrizio de Luiz Rosito Listo 5
}

\begin{abstract}
${ }^{1}$ Mestre em Geografia, Departamento de Ciências Geográficas, Universidade Federal de Pernambuco (UFPE), Recife/PE, Brasil. ORCID: https://orcid.org/0000-0002-9232-148X

Email: joaquim.xavier@ufpe.br

${ }^{2}$ Bacharel em Geografia, Departamento de Ciências Geográficas, Universidade Federal de Pernambuco (UFPE), Recife/PE, Brasil. ORCID: https://orcid.org/0000-0002-5293-0475

Email: edilsonsta@gmail.com
\end{abstract}

${ }^{3}$ Doutorando em Geografia, Departamento de Ciências Geográficas, Universidade Federal de Pernambuco (UFPE), Recife/PE, Brasil.

ORCID: https://orcid.org/0000-0003-0359-7247

Email: kaioc17@gmail.com

${ }^{4}$ Doutora em Geografia, Departamento de Ciências Geográficas, Universidade Federal de Pernambuco (UFPE), Recife/PE, Brasil. ORCID: https://orcid.org/0000-0002-9391-1211

Email: dannyavlis@yahoo.com.br

${ }^{5}$ Doutor em Geografia Física, Departamento de Ciências Geográficas, Universidade Federal de Pernambuco (UFPE), Recife/PE, Brasil.

ORCID: https://orcid.org/0000-0002-2664-1442

Email: fabrizio.listo@ufpe.br

\section{Resumo}

Estudos sobre processos erosivos em ambientes semiáridos ainda são bastantes escassos na literatura geomorfológica, principalmente, aqueles relacionados a erosão linear. O objetivo desse trabalho foi selecionar uma parcela representativa do conjunto ambiental do município de Belém do São Francisco, semiárido pernambucano, para detalhar, o papel desempenhado pelos elementos do contexto natural sobre a deflagração de processos erosivos. Para isso, foi realizado um mapeamento em microescala em uma parcela de $30 \mathrm{mx} 60 \mathrm{~m}$, por meio da análise de diferentes fatores condicionantes em uma ficha de campo descritiva. Os resultados apontaram que a interação sistêmica dos fatores condicionantes promove erosões com geometrias mais largas e alongadas com menor profundidade, comparando-se com processos erosivos comuns em áreas úmidas. Também foi verificado que a erosão linear, nestes ambientes, muitas vezes ocorre quando a erosão laminar já degradou o solo de maneira acentuada, proporcionando uma micro-topografia que favorece o escoamento de erosões lineares bem desenvolvidas.

Palavras-chave: Erosão; Semiárido; Mapeamentos de microescala.

\section{LINEAR EROSIONS IN THE PERNAMBUCO SEMIARID: EVALUATION OF A MICROSCALE EROSIVE PLOT IN THE SAN FRANCISCAN DEPRESSION}

\section{Abstract}

Studies on erosive processes in semi-arid environments are still quite scarce in the geomorphological literature, especially, those related to linear erosion. The objective of this work was to select a representative part of the environmental group of the municipality of Belém do São Francisco, Pernambuco semi-arid, to detail the role played by the elements of the natural context on the erosion of erosion processes. For this, we performed a microscale mapping in a $30 \mathrm{mX} 60 \mathrm{~m}$ plot, through the analysis of different conditioning factors in a descriptive field form. The results pointed out that the systemic interaction of the conditioning factors promotes erosion with wider and longer elongated geometries, compared with erosive processes common in wetlands. It has also been found that linear erosion in these environments often occurs when laminar erosion has already severely degraded the soil, providing a micro-topography that favors the flow of well-developed linear erosions.

Keywords: Erosion; Semiarid; Microscale mappings. 


\section{EROSIONES LINEALES EN LA REGIÓN SEMIÁRIDA DE PERNAMBUCO: EVALUACIÓN DE UNA PORCIÓN EROSIVA EN UNA MICROESCALA EN LA DEPRESIÓN DE SAN FRANCISCO}

\section{Resumen}

Los estudios sobre procesos erosivos en ambientes semiáridos aún son escasos en la literatura geomorfológica, especialmente, aquellos relacionados con la erosión lineal. El objetivo de este trabajo fue seleccionar una porción representativa del grupo ambiental en el municipio de Belém do São Francisco, una región semiárida en Pernambuco, para detallar el papel desempeñado por los elementos del contexto natural en el estallido de los procesos de erosión. Para esto, se realizó un mapeo a microescala en una parcela de $30 \mathrm{mX60m}$, a través del análisis de diferentes factores de acondicionamiento en un formulario de campo descriptivo. Los resultados mostraron que la interacción sistémica de los factores condicionantes promueve erosiones con geometrías más anchas y alargadas con menos profundidad, en comparación con los procesos erosivos comunes en áreas húmedas. También se descubrió que la erosión lineal, en estos entornos, a menudo ocurre cuando la erosión laminar ya ha degradado el suelo de manera marcada, proporcionando una micro-topografía que favorece el flujo de erosiones lineales bien desarrolladas.

Palabras-clave: Erosión; Semiárido; Mapeos de microescala.

\section{INTRODUÇÃO}

A erosão é um processo ocorrente em larga escala no Brasil em diferentes ambientes. Como exemplo, observam-se feições erosivas lineares tanto em ambientes mais úmidos, cujos índices pluviométricos são mais elevados, como em ambientes semiáridos, cuja precipitação anual é mal distribuída, espacialmente e temporalmente. Entretanto, o estudo de processos erosivos em ambientes semiáridos é ainda um dos temas mais escassos na geomorfologia brasileira, mesmo sendo apontada como um dos critérios para se avaliar a perda do solo e possíveis processos de desertificação (AGUIAR et al., 2006; SANTOS et al., 2011).

A região Nordeste é dominada em grande parte de ambientes semiáridos, ocupando um quinto do território brasileiro cuja abrangência é de 1.267 municípios conforme a delimitação realizada em 2017 pela ASA - Articulação Semiárido Brasileiro. A ocorrência de processos erosivos em áreas de baixa pluviosidade é um fator de divergência em muitos estudos erosivos, principalmente, nas classificações de erosão linear, que a subdividem em sulcos, ravinas e voçorocas (ALMEIDA FILHO et al., 1999), de difícil aplicação para as áreas mais secas.

Conforme Guerra (2007), as voçorocas caracterizam-se como incisões no solo com largura e profundidade superiores a cinquenta centímetros, na qual, tal definição é ainda complementada, segundo Almeida Filho et al. (1999), entre outros, pelo afloramento do lençol freático, conceito este facilmente diagnosticado em ambientes mais úmidos. Entretanto, nos ambientes mais secos, as voçorocas ocorrem mesmo sem a exposição de lençóis freáticos, considerando suas grandes dimensões/geometrias, visto que nestas áreas o lençol muitas vezes é inexistente, pois se tratam de formações antigas cuja forte predominância de rochas graníticas impede a infiltração da água e dificulta a formação destes; além de um regime pluviométrico inconstante.

A avaliação de processos erosivos em ambientes semiáridos, por ser um processo mais frequente do que se espera, necessita da compreensão e da aplicação de técnicas para avaliação de seus fatores condicionantes. Dessa forma, o mapeamento em parcelas erosivas de detalhe foi desenvolvido visando suprir o déficit de disponibilidade de dados em áreas desprovidas de imagens de satélite e de levantamentos temáticos e topográficos de maior detalhe.

Corrêa e Azambuja (2005) já haviam relatado que o semiárido nordestino possui uma grande importância de coleta de dados baseados em trabalho de campo, uma vez que a maior parte dos dados disponíveis não se refere à operação dos sistemas de superfície terrestre e sua interação. Assim, as técnicas de mapeamentos em microescala vêm sendo desenvolvidas em diversos contextos, como por exemplo, Corrêa e Azambuja (2005) em ambiente aluvial em clima semiárido, Vasconcelos et al. (2007) em encosta coluvionar em clima semiárido, Pereira et al. (2018) em encosta coluvionar em brejo de altitude, entre outros. Dessa forma, o objetivo desse trabalho foi selecionar uma parcela representativa do conjunto ambiental do município de Belém do São Francisco, semiárido pernambucano, para avaliar, em detalhe, o papel desempenhado pelos elementos do contexto natural sobre a deflagração de processos erosivos. O referido município está inserido na Depressão São Franciscana em um sistema de baixa pluviosidade, entretanto, é marcado pela ocorrência de diversas cicatrizes de processos erosivos lineares.

\section{METODOLOGIA}

Visando cumprir o objetivo deste trabalho, foi aplicado o método de mapeamento em microescala (mapeamento de parcela erosiva), partindo-se do pressuposto metodológico proposto por Corrêa e Azambuja (2005). Em campo, foi delimitada uma parcela representativa de dimensão de $30 \mathrm{~m} \times 60 \mathrm{~m}$, utilizando-se estacas para a delimitação dos extremos (Figura 1). Posteriormente, foram dimensionados e subdivididos em seu interior quadrantes (células) de $5 \mathrm{mx} 5 \mathrm{~m}$ com o uso de trenas. Foram utilizados os instrumentos de estação total e de receptor GPS para a coleta das coordenadas geográficas das extremidades e dos quadrantes interiores da parcela, bem como o registro da localização de feições pontuais de interesse (ex: cicatrizes erosivas).

Após a delimitação da parcela, partiu-se para o levantamento (observações de campo) de variáveis temáticas em uma ficha descritiva, tais como, a estrutura geológica (ígnea, metamórfica e/ou sedimentar); feições geomorfológicas do terreno (pedimentos, plaino aluvial, encostas coluviais, entre outras); cobertura superficial da paisagem (tipo do solo e/o tipos de sedimento); análise da cobertura vegetal (arbustiva, herbácea, etc.); padrões de uso da terra (agricultura, pecuária, solo exposto, etc.); identificação dos processos superficiais predominantes (fluxo laminar, erosão linear, salinização e deposição de aluviões, colúvios e leques de detritos). Ressalta-se que os mapeamentos das variáveis temáticas supracitadas ocorreram em cada célula (pixel) da parcela, utilizando-se além da ficha descritiva, um registro fotográfico e um croqui de campo em papel milimetrado. 
Após a etapa de campo e de coleta de dados, foram criados vetores para cada informação obtida em campo, por meio da sobreposição dos dados, a fim da elaboração de um mapa de parcela erosiva em escala de microdetalhe em ambiente SIG (Sistemas de Informação Geográfica), utilizando a extensão ArcMap do software Arcgis 10.4. Por fim, visando a quantificação dos dados morfométricos da feição erosiva inserida na parcela, tais como, comprimento, profundidade e largura, foi também calculado o volume de material erodido proposto por Guerra (2005) e Macedo et al. (2004), afim de investigar as prováveis causas da feição erosiva, possível evolução e grau de instabilidade para a região.

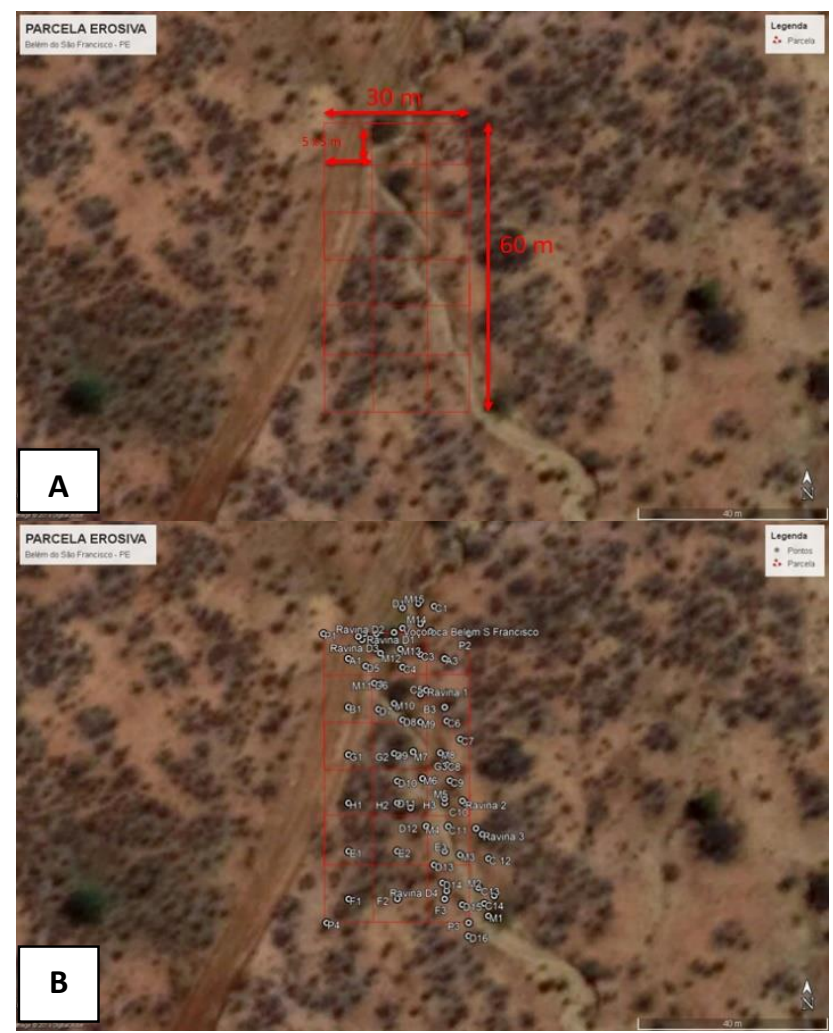

Figura 1 - Parcela erosiva em Belém do São Francisco-PE, A) Delimitação da parcela em campo; B) Levantamento de pontos por GPS. Fonte: elaborado pelos autores.

\section{RESULTADOS E DISCUSSÃO}

O município de Belém de São Francisco (Figura 2) está situado na Mesorregião do São Francisco (PE). É marcado por unidades litoestratigráficas (Complexo Belém do São Francisco, Complexo Cabrobó e Complexo Floresta) de diferentes períodos (Mesoproterozoico e Paleoproterozóico). Geologicamente, o embasamento cristalino é restrito as fraturas e as falhas contribuindo no quantitativo de água armazenada e na escassez hídrica; estando inserido na unidade morfoestrutal da Depressão Sertaneja (ROSS, 1992).

As condições climáticas são consideradas as mais severas de todo o estado de Pernambuco. Os índices de insolação chegam a
2.700 horas/ano, as taxas de precipitação são inferiores a $800 \mathrm{~mm}$ e a evaporação supera $2.000 \mathrm{~mm} /$ ano (MOURA et al., 2007). É no verão, entretanto, que as temperaturas ultrapassam os $30^{\circ} \mathrm{C}$ permitindo altas taxas de evapotranspiração, sendo também atuante no verão sistemas de chuvas que são trazidos pelo anticiclone do Atlântico sul.

Pedologicamente, predominam solos jovens (Neossolos Litólicos, Regolíticos e Quartzarênicos), solos salinos (Planossolos) e solos pouco profundos (Luvissolos). Dada a ocorrência de solos pouco profundos e com características morfológicas, físicas e químicas que favorecem o desencadeamento de processos, é comum a ocorrência de cicatrizes erosivas na área; além da baixa capacidade de armazenamento hídrico.

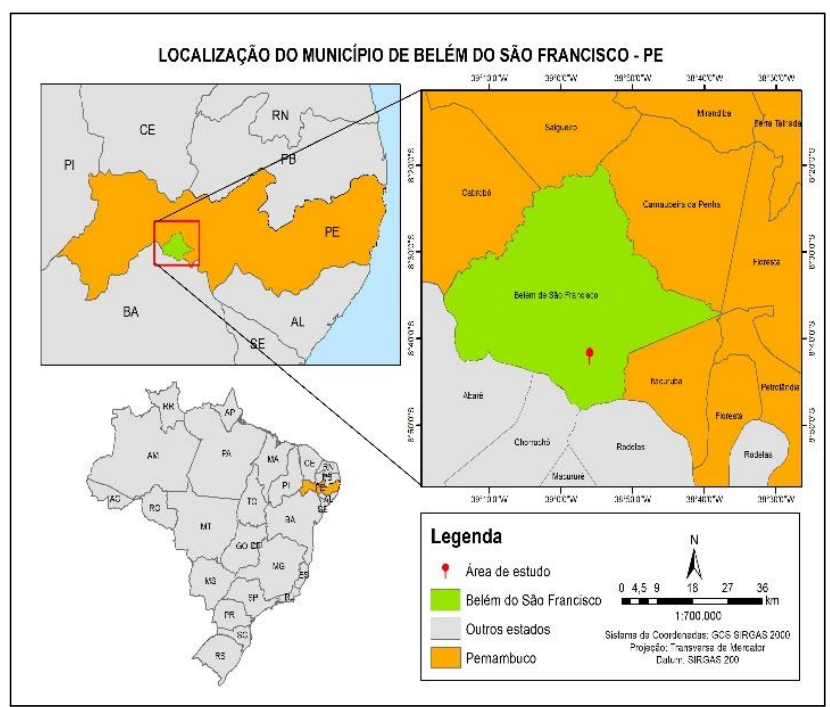

Figura 2 - Localização do município de Belém do São Francisco$P E$, onde está inserida a parcela erosiva avaliada (destaque vermelho). Fonte: elaborado pelos autores.

Com relação à cobertura vegetal, observações de campo permitiram a sua classificação como caatinga hiperxerófila constituídas por formações arbóreo-arbustivas. As formações lenhosas com elevado grau de xerofitismo, predominantemente, arbustivas e pouco densas, com espécies de porte baixo e espinhentas, devido suas características, pouco protegem o solo dos processos iniciais da erosão.

A parcela (Figura 3) encontra-se inserida na unidade geomorfológica da Depressão Sertaneja caracterizada por uma depressão Interplanáltica cuja morfologia é resultante de uma pediplanação intensa em rochas mesoproterozoicas e neoproterozoicas da Província Borborema. Predominam rochas metamórficas de idade mesoproterozoica como mármores, anfibolitos, migmatitos e ortognaisses (FERREIRA; DANTAS; SHINZATO, 2014). Nesse contexto, a parcela apresentou em toda a sua área um pedimento de superfície aplainada com baixa declividade que, embora não aumente a energia do escoamento superficial, ainda se caracteriza por uma área de perda de sedimento (ambiente degradacional). 
Em toda a extensão da parcela há presença de planossolos com horizontes superficiais pouco espessos e de textura arenosa, com queda abrupta para o horizonte B (com considerável aumento de argila), tornando-o pouco permeável e favorecendo a ocorrência de processos erosivos. Essa configuração de textura e de estrutura associada a condição de argilas expandidas quando hidratadas $(2: 1)$ torna esse solo pouco resistente a desagregação de suas partículas.

A condição climática é de semiaridez quente com chuvas concentradas em curtos períodos. As chuvas de intensidade significativa em curtos períodos associados às características pedológicas favorecem a dinâmica de processos denudacionais observados na parcela, tais como, erosão laminar, erosões lineares e processos erosivos concentrados em canais de drenagem efêmeros.

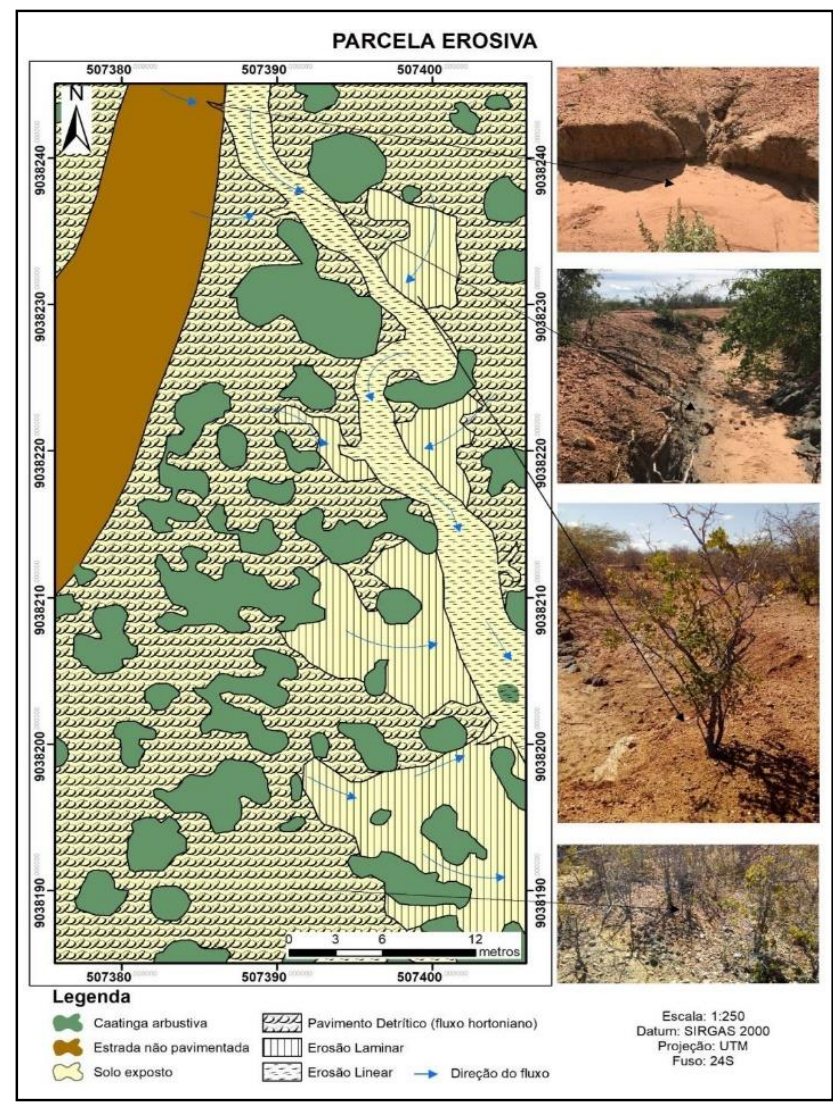

Figura 3 - Mapeamento em microescala de parcela erosiva, na qual, destacam-se a presença de planossolos, incisões erosivas, pavimentos detríticos e caatinga arbustiva. Fonte: elaborado pelos autores.

A cobertura vegetal da parcela é, predominantemente, caatinga arbustiva, com predomínio de espécies das famílias Euphorbiaceae (ex: faveleira) e Cactaceae (ex: xique xique). Não foram observados usos agrícolas ou outra intervenção antrópica de grande magnitude, somente indícios de pecuária extensiva de caprinocultura com pouca exploração e de baixa expressividade. Há uma estrada não pavimentada a noroeste da parcela que causou a compactação do solo, influenciando no comportamento/alteração do fluxo superficial.

Dentre os processos superficiais presentes na parcela (Figura 3), foi identificado a ocorrência de erosão laminar a partir da diferenciação da coloração do solo, da perda do horizonte A em algumas situações e da presença de pavimento detrítico, que evidenciam o fluxo hortoniano, comum nas áreas mais secas. Estes caracterizam-se como um fluxo não canalizado cujas frações mais finas do solo são carreadas para os leitos dos rios e, assim, desenvolve-se um pavimento rudáceo sobre os baixos interflúvios (CORRÊA e AZAMBUJA, 2005).

Observou-se também uma grande incisão originada por erosão linear (Figura 4) ainda ativa, no sentido norte-sudeste da parcela, apresentando aspecto mais alongado e com menor profundidade em comparação a erosões comuns em zonas úmidas, conforme os valores geométricos indicados na Tabela 1.

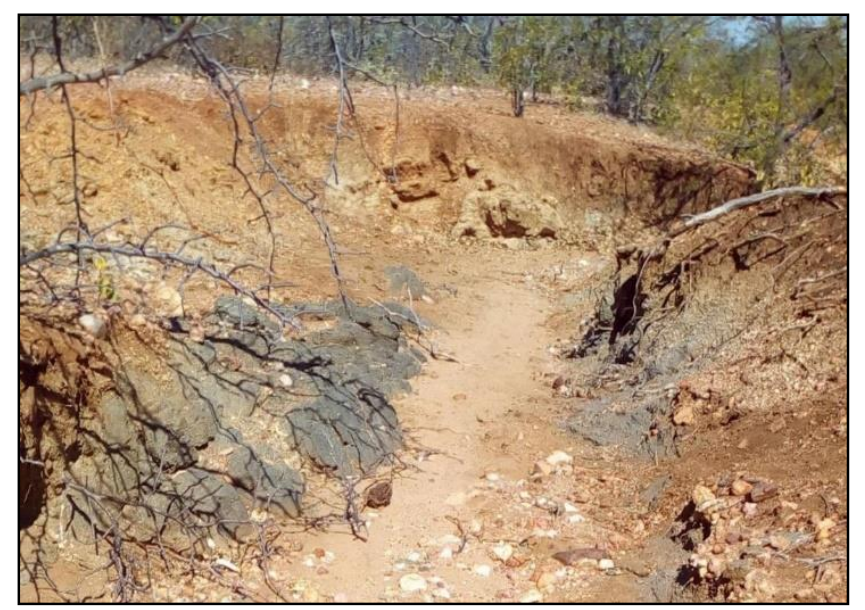

Figura 4 - Erosão linear presente na parcela avaliada. Fonte: elaborado pelos autores.

Tabela 01. Valores geométricos da principal erosão linear inserida na parcela (Figura 4). Fonte: elaborado pelos autores.

\begin{tabular}{l|l}
\hline Comprimento & $50,7 \mathrm{~m}$ \\
\hline Largura mínima & $1,90 \mathrm{~m}$ \\
\hline Largura máxima & $5,03 \mathrm{~m}$ \\
\hline Profundidade máxima & $0,80 \mathrm{~m}$ \\
\hline Área & $143,32 \mathrm{~m}^{2}$ \\
\hline Volume & $46483,47 \mathrm{~m}^{3}$ \\
\hline
\end{tabular}

A presença de sedimentos finos de transporte por fluxo canalizado na incisão indica que a mesma possui características aluviais, que em chuvas torrenciais, além do desenvolvimento do processo erosivo, também se comportam como canais efêmeros. Em outras palavras, os processos erosivos evoluem para canais efêmeros na área.

Há também muitas incisões menores (Figura 5) ao longo da erosão principal, remontantes a direção do fluxo superficial, tendo como preferência de direção as áreas em que o fluxo passa a ser canalizado. Isso evidencia a certa conexão evolutiva entre erosão laminar e linear, conforme Oliveira (2007), ao sugerir o desenvolvimento de erosões conectadas a redes de drenagem efêmeras nos modelos de evolução de voçorocas. 


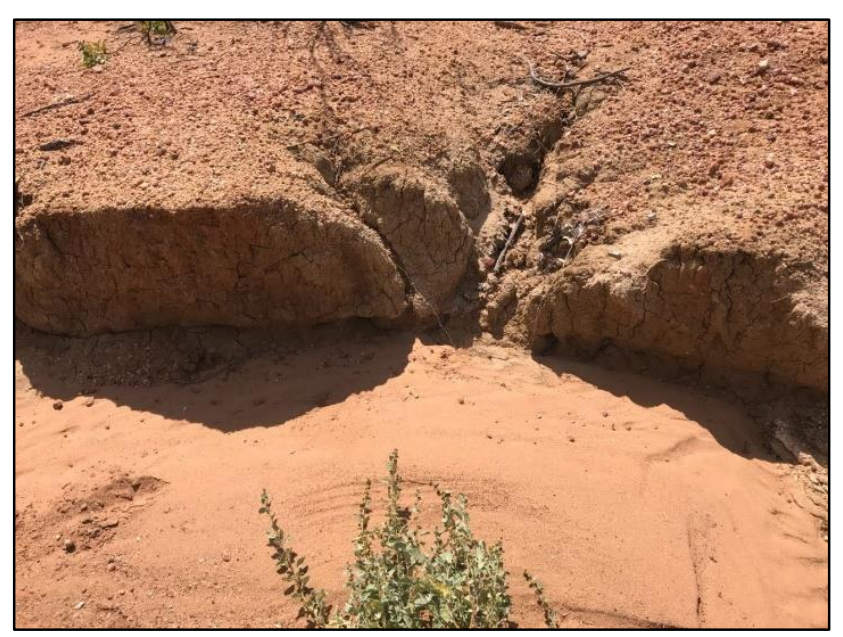

Figura 5 - Incisões menores na borda da erosão principal. Fonte: elaborado pelos autores.

\section{CONSIDERAÇÕES FINAIS}

A metodologia de mapeamento de detalhe mostrou-se satisfatória, sobretudo, para a avaliação do comportamento do processo erosivo. Neste sentido, cumpre tanto a função de obtenção de dados acurados em detalhe, quanto se torna uma boa ferramenta que auxilia na sistematização das informações empíricas obtidas pelas observações em campo, principalmente, no desenvolvimento de processos erosivos no semiárido.

A parcela avaliada demonstra a ocorrência de solos com alta suscetibilidade a erosão (ex. planossolos). Nos contextos semiáridos, o processo erosivo muitas vezes é deflagrado nos momentos de precipitação abrupta, geralmente de curta duração, associados a solos de baixa resistência. Devido as características planas dos pedimentos inseridos na Depressão Sertaneja, o processo erosivo apresenta geometria mais larga e alongada com menor profundidade em comparação as erosões comuns em área úmida. Além disso, apresenta características evolutivas, das quais a erosão linear muitas vezes ocorre após a desagregação dos solos causadas pelas erosões do tipo laminar; proporcionando uma micro-topografia que permita o escoamento canalizado. Tal características faz com que as erosões lineares estejam conectadas em redes, remontantes, a partir de incisões erosivas lineares préexistentes.

\section{REFERÊNCIAS}

AGUIAR, M. I.; MAIA, S. M. F.; OLIVEIRA, T. S.; MENDONÇA, E. S.; FILHO, J. A. A. Perdas de solo, água e nutrientes em sistemas agroflorestais no município de Sobral, CE. Revista Ciência Agronômica, v. 37, n. 3, p. 270$278,2006$.

ALMEIDA FILHO. G. S; GOUVEIA, M. I. F; RIDENTE JUNIOR, J. L; CANIL, K. Prevenção e Controle da Erosão Urbana no Estado de São Paulo. In: Congresso Brasileiro de Engenharia Sanitária e Ambiental, 21., 1999, João Pessoa/PB. Anais... João Pessoa: UFPB, 1999.
CORRÊA, A. C. B.; AZAMBUJA, R. N. Avaliação Qualitativa em Microescala da Estabilidade da Paisagem em Áreas Sujeitas a Desertificação no Ambiente Semiárido do Nordeste do Brasil. In: Simpósio Brasileiro De Geografia Física Aplicada, 11., 2005, São Paulo. Anais... São Paulo: USP, 2005. p. 5839 - 5847.

FERREIRA, R. V.; DANTAS, M. E.; SHINZATO, E. Origens das Paisagens. In: TORRES, F. S. M.; PFALTZGRAFF, P. A. S. Geodiversidade do Estado de Pernambuco. Recife: CPRM, 2014. Cap. 4. p. 51-71.

GUERRA, A. J. T. Experimentos e monitoramentos em erosão dos solos. Geography Department, University Of Sao Paulo, [s.1.], p.32-37, 2005. Universidade de Sao Paulo Sistema Integrado de Bibliotecas - SIBiUSP. http://dx.doi.org/10.7154/rdg.2005.0016.0003.

GUERRA, A. J. T. O início do processo erosivo. In: GUERRA, A. J. T.; SILVA, A. S.; BOTELHO, R. G. M. (Org.). Erosão e conservação dos solos: conceitos, temas e aplicações. Rio de Janeiro: Bertrand Brasil, 2007. Cap. 1. p. 15-55.

MACEDO, E. S.; OGURA, A. T.; CANIL, K.; ALMEIDA FILHO, G. S.; GRAMANI, M. F.; SILVA, F. C.; CORSI, A. C.; MIRANDOLA, F. A. Modelos de fichas descritivas para áreas de risco de escorregamento, inundação e erosão. In: Simpósio Brasileiro de Desastres Naturais, 1., 2004, Florianópolis. Anais... Florianópolis: GEDN/UFSC, p. 892907. (CD-ROM).

MOURA, M. S. B.; GALVINCIO, J. D.; BRITO, L. T. L.; SOUZA, L. S. B.; SÁ, I. I. S.; SILVA, T. G. F. Clima e água de chuva no Semiárido. In: BRITO, L. T. L.; MOURA, M. S. B.; GAMA, G. F. B. (Ed.). Potencialidades da água de chuva no Semi-Árido brasileiro. Petrolina: Embrapa SemiÁrido, 2007. p. 37-59.

OLIVEIRA, M. A. T. Processos Erosivos e Preservação de Áreas de Risco de Erosão por Voçorocas. In: GUERRA, A. J. T.; SILVA, A. S.; BOTELHO, R. G. M. (Org.). Erosão e Conservação dos Solos: Conceitos, temas e aplicações. 3. ed. Rio de Janeiro: Bertrand Brasil, 2007. Cap. 2. p. 57-100.

PEREIRA, T. M.; CARDOSO, A. H. R. P.; SANTOS, A. F. R.; SILVA, B. A. A.; LISTO, F. L. R.; CORRÊA, A. C. B. Mapeamento em Microescala de Parcela Erosiva de Encosta em Santa Cruz da Baixa Verde, Sertão Pernambucano. In: SIMPÓSIO NACIONAL DE GEOMORFOLOGIA, 12., 2018, Crato. Anais.... Crato: Urca, 2018. p. 1 - 7.

ROSS, J. L. S. Registro cartográfico dos fatos geomorfológicos e a questão da taxonomia do relevo. Revista do Departamento de Geografia. 17-29 pp. São Paulo, IG- USP, 1992.

SANTOS, J. C. N.; PALÁCIO, H. A. Q.; ANDRADE, E. M.; MEIRELES, A. C. M.; ARAÚJO NETO, J. R. Runoff and soil and nutrient losses in semiarid uncultivated fields. Revista Ciência Agronômica, v.42, p.813-820, 2011. 
VASCONCELOS, T. L.; SOUZA, S. F.; DUARTE, C.C.; MELIANI, P. F.; ARAÚJO, M. S. B.; CORRÊA, A. C. B. Estudo Morfodinâmico em Área do Semiárido do Nordeste Brasileiro: Um mapeamento geomorfológico em microescala. Revista de Geografia, Recife, v. 24, n. 2, p.3649, ago. 2007.

\section{AGRADECIMENTOS}

Os autores agradecem à Coordenação de Aperfeiçoamento de Pessoal de Nível Superior (CAPES) pelo financiamento desta pesquisa (Proc. 310452/2018-0); à Pró-Reitoria para assuntos de Pesquisa e Pós-graduação (PROPESQ) da UFPE pelo financiamento do projeto "Zoneamento de processos erosivos e deslizamentos de terra para o estado de Pernambuco: banco de dados georreferenciado, ensaios de campo e de laboratório e modelagem matemática" (Proc. 23076026625201931/2019); ao Laboratório de Geomorfologia e Geotecnologias (GEOTEC) da UFPE e ao Grupo de Pesquisa em Geotecnologias Aplicadas a Geomorfologia de Encostas e Planícies (ENPLAGEO) da UFPE pela estrutura disponibilizada.

Recebido em: 20/11/2019

Aceito para publicação em: 28/07/2020 